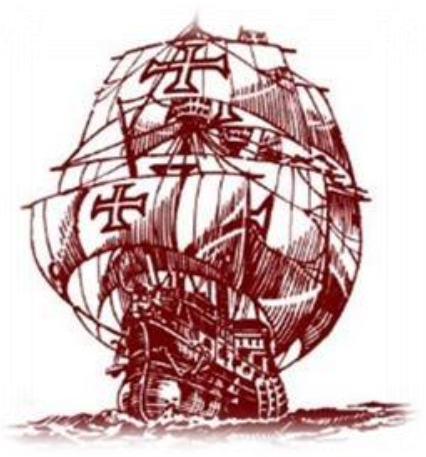

Nau Literária: crítica e teoria de literaturas

www.seer.ufrgs.br/nauliteraria

ISSN 1981-4526 - PPG-LET-UFRGS - Porto Alegre

Vol. 11 N. $01-2015$

100 anos da geração Orpheu

\title{
A desconstrução do imaginário imperialista português no romance As naus, de António Lobo Antunes
}

\author{
Leonardo von Pfeil Rommel ${ }^{1}$
}

\begin{abstract}
Resumo: Historicamente concebida como uma nação forjada pelas grandes glórias e descobrimentos possibilitados pelas navegações, Portugal construiu seu imaginário nacional em um contexto permeado pela ideologia imperialista, visando sempre conquistar novas terras ao redor do Planeta, assegurando, assim, o progresso e o avanço da pátria $\mathrm{O}$ presente estudo busca analisar o processo de desconstrução do imaginário nacional português no romance As naus (1988), de António Lobo Antunes. Utilizando-se de personagens históricos e de uma mescla de diferentes tempos, por meio da ficção, o autor constrói um espaço próprio, onde discute e problematiza o processo da colonização e da valorização do passado histórico no iimaginário da nação portuguesa.
\end{abstract}

Palavras-chaves: Imaginário; imperialismo; Portugal; António Lobo Antunes.

Abstract: Historically designed as a nation forged by the great glories and discoveries enabled by the navigations, Portugal has built its national imaginary on a context surrounded by the imperialist ideology, always seeking to conquer new lands around the globe, ensuring the progress and advancement of the country. This research aims to analyze the process of deconstruction of the Portuguese national imaginary on the novel As naus (1988), from António Lobo Antunes. Using historical characters and a mix of different times, through fiction, the author constructs a space, in which he discusses and questions the process of colonization and appreciation of the historical past on the imaginary of the Portuguese nation.

Keywords: Imaginary; imperialism; Portugal; António Lobo Antunes.

Historicamente concebida como uma nação forjada pelas grandes glórias e descobrimentos possibilitados pelas navegações, Portugal constituiu seu imaginário nacional num contexto permeado pela ideologia expansionista, que visava conquistar novas terras ao redor do Planeta, para, assim, assegurar o progresso e o avanço da nação, valorizando ideais como a bravura e a coragem.

O empreendimento das navegações e da expansão territorial sempre foi ideologicamente apoiado e justificado pela monarquia portuguesa como uma forma de manutenção da imagem da nação como grande Império. Ao mesmo tempo, o processo de colonização foi sempre dotado

\footnotetext{
${ }^{1}$ Mestrando em literatura comparada (UFPEL) e bolsista CAPES.
} 
de características místicas, cenário em que os portugueses foram levados a acreditar que tal empreendimento seria responsável pela propagação da fé católica pelo mundo.

O presente estudo busca analisar o processo de desconstrução do imaginário nacional português no romance As naus (2011), de António Lobo Antunes, publicado originalmente em 1988, mais de uma década após o final do colonialismo e do regime salazarista.-Utilizando-se de personagens históricos e de uma mescla de diferentes tempos, por meio da ficção, o autor constrói um espaço próprio, onde discute e problematiza o processo da colonização e da valorização do passado histórico no imaginário da nação portuguesa.

Na narrativa construída por António Lobo Antunes, vários personagens históricos, célebres durante o período das grandes navegações e descobrimentos, retornam à terra natal após o fim do processo de colonização, na década de 1970, e acabam se entrecruzando nas mais diversas relações e negócios ilícitos.

A cidade para a qual regressam os personagens chama-se Lixboa, nome alterado pelo autor como forma de demarcar esse novo espaço ficcional, onde a história oficial é subvertida de forma que o leitor tenha acesso ao fracasso do período colonial e dos grandes descobrimentos nacionais.

Numa narrativa que mescla constantemente o uso da primeira e terceira pessoa, podese acompanhar o desfecho tragicômico dos efeitos da excessiva valorização das conquistas do passado e da colonização. Os heróis nacionais regressam anônimos a Portugal, e são obrigados a viver de forma miserável pelas periferias de uma cidade para eles irreconhecível, destruída pela miséria e assolada pelas centenas de milhares de retornados.

Como forma de evidenciar o drama dos retornados das colônias africanas após o final do regime salazarista, com a Revolução dos Cravos, em abril de 1974, António Lobo Antunes transforma ícones da identidade e do imaginário nacional em meras vítimas da pobreza e do malfadado sistema político que geriu a nação durante o período ditatorial. Muitos dos retornados, como Vasco da Gama, Manuel de Sousa de Sepúlveda e Pedro Álvares Cabral, são excluídos por suas famílias e não mais aceitos pela população em geral da cidade.

Grandes navegadores, líderes religiosos e até mesmo importantes figuras literárias, como Luís de Camões, são transformados em vítimas de um país que ao longo de sua existência mergulhou em um processo de contemplação e valorização de um passado histórico ultrapassado e inconcebível para sua verdadeira realidade.

O mito messiânico do Sebastianismo, de presença marcante no imaginário e na cultura portuguesa, desempenha na trama o papel de uma alegoria fracassada, onde o sonho jamais se uniu com a realidade e onde alguns personagens, um grupo de doentes tuberculosos dotados de 
grande valor nacionalista, inutilmente aguardam que a ilusão se torne real a partir do improvável anunciado regresso do monarca português.

As naus (2011) subverte as grandes epopeias épicas narradas em Os Lusíadas, de Camões, e em Mensagem, de Pessoa, pois não glorifica o tempo próspero das navegações e seus protagonistas, nem tampouco busca reerguer o sonho e a esperança de um passado mítico nacionalista, rompendo, assim, com as principais formas narrativas que sempre permearam o imaginário e participaram da formação e consolidação da identidade portuguesa.

Projectando nos vultos históricos de navegadores, escritores, heróis e missionários a inditosa aventura de retorno dos colonos no pós-25 de abril de 1974, multiplicando neles as marcas do descalabro e da irrisão (físicas e morais), recorrendo a efeitos de burlesco, de sátira e de rebaixamento carnavalescos, inverte António Lobo Antunes o assaz mitificado e glorioso sentido dos descobrimentos portugueses, reescrevendo assim Os Lusíadas em modo paródico. (SEIXO et al., 2009, p. 152).

Percebe-se que com a intensa carnavalização e o emprego de tom burlesco ao descrever os heróis nacionais, a narrativa rompe com a tradição literária consolidada pela exaltação do passado e do imaginário mítico. Segundo Maria Alzira Seixo (2009), o romance reescreve de modo paródico a principal narrativa da literatura portuguesa, desmistificando assim o passado e revelando o presente de modo irônico e direto.

Luís de Camões, o Homem de nome Luís, é representado na narrativa como um retornado de Angola. Ele, no regresso a Lixboa, insiste em carregar consigo o caixão do pai, vítima de uma bala perdida nos confrontos entre a guerrilha de libertação nacional e as tropas do exército colonial.

Durante a viagem de regresso a Portugal, faz amizade com um homem chamado Dom Miguel de Cervantes Saavedra, espanhol que vivia do ramo da jogatina em Moçambique e estava retornando a Madrid a fim de completar o romance, que estava sempre escrevendo em

folhas soltas e papéis desprezados, intitulado Dom Quixote. Ao seu lado nesta viagem está Vasco da Gama, o primeiro comandante da frota marítima portuguesa a navegar da Europa para a Índia. Reformado, Vasco da Gama passava longas horas entregue ao vício do jogo de cartas.

Estes três peculiares personagens passam todo o tempo da viagem a jogar cartas e a beber. Ao chegarem a Lixboa perdem horas entretidos em disputas sem fim. Enquanto isso, o Homem de nome Luís aguarda seus pertences chegarem em outro navio, sentado pacientemente sobre o caixão do pai, que insiste em conduzir até a Europa, apesar das negativas das autoridades.

Após se separarem, o Homem de nome Luís desiste de esperar que os seus pertences aportem em Lixboa e parte para uma epopeia ao longo da descaracterizada cidade, em busca de 
um enterro digno para o corpo do seu pai. A partir desta jornada pela cidade de Lixboa, que adquire contornos épicos em meio à miséria e às novidades de uma terra estrangeira, ele busca inspiração para escrever os seus famosos versos, intitulados Os Lusíadas.

O caixão, que o Homem de nome Luís carrega consigo, desempenha o papel de uma alegoria burlesca do colonialismo europeu. Representa um último fardo inutilmente carregado pelos nacionalistas quando do seu regresso ao reino após a independência das colônias africanas.

Sendo assim, percebe-se na narrativa construída por António Lobo Antunes, que a imagem do maior poeta nacional está intimamente ligada ao fracasso do nacionalismo extremado e da valorização de um passado de conquistas. Sua representação refere a um fardo inútil e ultrapassado, que ironicamente estava a ser carregado por toda a História e ainda sobrevivia no imaginário português.

Durante suas andanças pelas surreais ruas da cidade de Lixboa, em busca de inspiração para os seus poemas heroicos, o Homem de nome Luís acaba encontrando a estátua erguida em sua homenagem, agora rodeada de pombos e de cães de rua. Presencia, ainda, uma cena histórica que lhe desperta a atenção - a fatídica partida do rei D. Sebastião para Alcácer Quibir, episódio mítico do imaginário nacionalista português.

De modo que fui moendo episódios heroicos, parando a tomar notas nas retrosarias iluminadas,
até desembocar na praça da minha estátua, mãe, com centenas de pombos adormecidos nas
varandas em atitudes de loiça e cães que alçavam a pata no pedestal da minha glória, e embora
o bagaço me atrapalhasse as pernas e me obrigasse a arrastar os sapatos numa marcha de
trombose, consegui alcançar um troço de escadas entre dois becos, de onde se via ao mesmo
tempo o monumento, os comboios para Cascais e as lanternas de pesca das traineiras do rio, e
precisamente nessa altura, estimados leitores, a Rua do Carmo acendeu-se de um cortejo de
tochas e de risos de pajens, alabardas picavam o asfalto, adenoides de ginetes fungavam, e o rei
D. Sebastião surgiu a cavalo rodeado de validos, arcebispos e privados, vestido de uma armadura
de bronze e de um elmo de plumas, e desapareceu para as bandas de pelourinho da Câmara,
seguido pelo espanto dos polícias e dos guardas-nocturnos, a caminho de Alcácer Quibir.
(ANTUNES, 2011, p. 123).

No ano de 1578, D. Sebastião parte para Alcácer Quibir, no Marrocos, a fim de realizar uma cruzada para combater tropas marroquinas e conquistar alianças econômicas e novos domínios terrestres. As tropas lusas, no entanto, acabam sendo dizimadas em pouco tempo, e o rei português desaparece sem deixar rastros.

As consequências desta batalha foram fatídicas para o reino de Portugal, uma vez que no embate, além de perderem seu monarca e comandante, vários nomes da nobreza também morreram ou foram feitos prisioneiros pelas tropas marroquinas. Pelo rei não ter deixado herdeiros para o trono, Portugal foi anexado à Espanha pelo rei Filipe II, a quem neste caso 
cabia a linha de sucessão. Assim, durante 60 anos Portugal perdeu a sua independência política e econômica e se viu sob o domínio castelhano.

A partir daí o retorno de D. Sebastião adquire contornos de um movimento místico e messiânico, pois revela os anseios da população portuguesa, que por anos espera o improvável regresso do rei, a fim de reassumir o trono de Portugal e libertar o país do domínio da coroa espanhola. A imagem do regresso messiânico do seu governante faz parte do imaginário nacionalista português, e foi alimentada e explorada pela literatura e cultura nacional ao longo de vários séculos.

Ao analisar o mito e as consequências do sebastianismo na cultura e imaginário nacional, Eduardo Lourenço (1999, p. 46) afirma que "Quem desaparecera no areal era um adolescente imaturo, vítima de sonhos mal sonhados. Era um rei frágil de um reino frágil que a sua morte punha à beira da inexistência".

O sebastianismo é retratado no romance As naus (2011) como um sonho, um delírio ingênuo de nacionalistas doentes, entre eles o Homem de nome Luís, que inutilmente ao final da narrativa dirigem-se à beira do mar para esperar pelo regresso do rei à pátria, em meio a uma neblina que anunciaria a sua chegada.

Esperámos, a tiritar no ventinho da manhã, o céu de vidro das primeiras horas de luz, o nevoeiro
cor de sarja do equinócio, os frisos de espuma que haveriam de trazer-nos, de mistura com os
restos de feira acabada das vagas e os guinchos de borrego da água no sifão das rochas, um
adolescente loiro, de coroa na cabeça e beiços amuados, vindo de Alcácer Quibir com pulseiras
de cobre trabalhado dos ciganos de Carcavelos e colares baratos de Tânger ao pescoço, e tudo o
que pudemos observar, enquanto apertávamos os termómetros nos sovacos e cuspíamos
obedientemente o nosso sangue nos tubos do hospital, foi o oceano vazio até à linha do horizonte
coberta a espaços de uma crosta de vinagreiras, famílias de veraneantes tardios acampados na
praia, e os mestres de pesca, de calças enroladas, que olhavam sem entender o nosso bando de
gaivotas em roupão, empoleiradas a tossir nos lemes e nas hélices, aguardando, ao som de uma
flauta que as vísceras do mar emudeciam, os relinchos de um cavalo impossível. (ANTUNES,
2011, pp. 181-182).

A derrota em Alcácer Quibir ficou marcada na memória nacional como um símbolo atemporal de um desastre e de uma morte coletiva, e representa o início de um período de nostalgia no imaginário nacional português. Destarte, a espera pelo milagroso e redentor regresso de D. Sebastião obriga sempre a nação a olhar o passado e aguardá-lo como resposta e salvação para o futuro.

No seu romance, António Lobo Antunes faz com que ao final do Colonialismo todos os grandes nomes da história nacional, responsáveis pelas navegações e descobrimentos, regressem a Portugal. Nas entrelinhas, o autor evidencia suas vidas mesquinhas e toda a tragédia que o período representou para uma nação que se apequenou, perdida em grandes ambições e sonhos místicos de conquista e de expansão do Império nacional. 
A maior parte dos retornados das colônias africanas é hospedada no Residencial Apóstolo das Índias, um edifício em péssimas condições estruturais, cercado pela pobreza e pela destruição da cidade de Lixboa, para onde o governo encaminhava primeiramente quem estivesse reentrando no país. Essa passagem do romance faz menção aos problemas sociais e de moradia que acometeram Portugal no final da colonização, quando centenas de milhares de pessoas retornaram de súbito ao país após a independência das colônias.

Alguns líderes religiosos, principais responsáveis pela catequização dos habitantes locais, e os principais apoiadores das viagens marítimas e descobrimentos, são representados no romance como donos de casas noturnas de má fama e como agenciadores e responsáveis pelo ramo da prostituição em Lixboa.

Francisco Xavier, um dos pioneiros da catequização nas terras descobertas no período das grandes navegações e fundador da Companhia de Jesus, considerado como o missionário que mais converteu povos ao Cristianismo, denominado de Apóstolo do Oriente devido à sua marcante atuação na Índia e Japão, é representado por António Lobo Antunes como o coordenador do Residencial Apóstolo das Índias. Nesse local, Francisco Xavier agencia mulheres entre os retornados para o meio da prostituição e administra negócios com casas noturnas.

Percebe-se uma crítica à religião católica e sua participação no Colonialismo, uma vez que, ao invés de converter povos ao Cristianismo e buscar sua instrução, o principal missionário português converte os moradores do residencial para a prostituição e os explora indevidamente. Ao inventar créditos e taxas, faz com que se perpetuem como devedores e, assim, não possam jamais sair de sua pensão.

A grande massa de retornados que invade Portugal após o final do Colonialismo evidencia vários problemas sociais, entre eles a questão da moradia, uma vez que o país não estava pronto para, repentinamente, receber tantas pessoas. O regresso dos colonos portugueses, portanto, assume um papel revelador para a cultura nacional, evidenciando o fim dos tempos da dominação política e econômica nas colônias africanas.

Quanto ao povo português - que a sério nada conhecia do fabuloso e mágico império - só tomará realmente consciência dos acontecimentos quando após as independências de Angola e Moçambique centenas de milhares de retornados invadem de súbito a pacífica e bonacheirona terra lusitana [...]. (LOURENÇO, 2007, p. 63).

O crítico literário e ensaísta Eduardo Lourenço evidencia que essa diáspora de portugueses que migraram da África para Portugal acabou por evidenciar uma série de problemas sociais do país, os quais eram mascarados pela ditadura salazarista. O retorno destas 
centenas de milhares de pessoas fez com que o país passasse a se confrontar com seus problemas internos e com suas dificuldades, deixando de ver o mundo a partir de uma posição dominante e colonialista.

$\mathrm{Na}$ narrativa de António Lobo Antunes, a grande maioria dos retornados reside no residencial gerido pelo missionário Francisco Xavier, enquanto que um casal retornado da Guiné Bissau é realocado pelo governo português em um hotel de luxo. Já o Homem de nome Luís acaba por conseguir abrigo em um hospital para tuberculosos, adaptado pelo governo como moradia devido à falta de espaço para o grande número de pessoas que regressa ao país.

O famoso navegador Manuel de Sousa de Sepúlveda, conhecido pela História nacional por sobreviver heroicamente a um naufrágio e vagar durante meses pela África em busca de socorro, em As naus (2011) vive em Angola, envolvido em esquemas ilícitos do tráfico de pedras preciosas e diamantes com a polícia política portuguesa, a Pide. Ao regressar após a Revolução, se vê abandonado e ignorado pelos familiares e encontra seu apartamento na praia ocupado por um grupo de ciganos e de miseráveis retornados das colônias africanas, sendo obrigado a ir morar no fatídico residencial.

Diogo Cão, primeiro navegador português a desbravar a costa sudoeste da África, após regressar de Luanda, onde desempenhava funções administrativas de fiscal da Companhia das Águas, também é morador do residencial. Vive em completa resignação, amparado pelo vício do álcool. A maioria dos moradores desconfia serem falsas as histórias que costuma narrar a respeito de suas viagens marítimas e descobrimentos, inclusive seu amigo, Pedro Álvares Cabral.

O primeiro amigo que fizeram no Residencial Apóstolo das Índias dormia três colchões adiante, chamava-se Diogo Cão, tinha trabalhado em Angola de fiscal da Companhia das Águas, e quando à tarde, depois da mulata partir para o bar, se sentava comigo e com o miúdo nos degraus da pensão a ver nas ripas dos telhados o frenesim das rolas, anunciava-me, já de voz incerta, beberricando de um frasco oculto no forro do casaco, que há trezentos, ou quatrocentos, ou quinhentos anos comandara as naus do Infante pela Costa de África abaixo. Explicava-me a melhor forma de estrangular revoltas de marinheiros, salgar a carne e navegar à bolina e de como era difícil viver nesse árduo tempo de oitavas épicas e de deuses zangados, e eu fingia acreditálo para não contrariar a susceptibilidade das suas iras de bêbedo, até ao dia em que abriu a mala à minha frente e debaixo das camisas e dos coletes e das cuecas manchadas de vomitado e de borras de vinho, dei com bolorentos mapas antigos e um registro de bordo a desfazer-se. (ANTUNES, 2011, p. 47).

O fim do Colonialismo representa um marco para o imaginário nacionalista de Portugal. A partir dele, o país encontra a necessidade de repensar e reorganizar a sua identidade nacional, antes construída em bases que valorizavam a expansão, o domínio de outros povos e o avanço da noção de Império. 
Ao analisar os impactos e interferências do final do Período Colonial na cultura e no imaginário português, Lourenço (1999, p.100) defende que o povo de Portugal vive em um estado de saudade contemplativa das glórias anteriores. Segundo ele, ao revisitar a história, o português não se sente melancólico nem triste, mas simplesmente saudoso do seu onírico passado imperial, que, a bem dizer, jamais chegou a se concretizar verdadeiramente.

O imaginário do povo português, após a Revolução dos Cravos, segue contemplativo e saudoso de um passado distante, que nem chegou a ser totalmente real. O regresso de Portugal para junto da Europa na década de 1970 fez com que fossem sentidos os reais efeitos do final do Colonialismo e da expansão nacional ao redor do mundo.

Há mais de meio século que centenas de milhares de portugueses vivem na Europa no meio de povos que os aceitaram e que eles aceitam. Mas poucos suspeitam a que ponto essa gente da extrema Europa, ibérica, católica - frequentando ainda igrejas que eles mesmos desertaram e em vias de as desertar também -, vem de um outro mundo e continua a viver nesse mundo que deixou. (LOURENÇO, 2007, p. 9).

O imaginário português encontra-se intimamente ligado ao passado, à valorização da noção de Império. Mesmo após o traumático regresso do Colonialismo, ainda se pode perceber essa valorização do passado e das conquistas, como se o português tivesse desaprendido a viver consigo mesmo, dentro das suas próprias fronteiras físicas e imaginárias.

O processo colonialista, falido e fracassado, deixou resquícios terríveis para os povos africanos, mas também para o colonizador europeu, que se viu desterrado, entregue a um melancólico e desesperançado retorno à casa própria, que o imaginário sempre havia insistido em dispersar pelos quatro cantos do Planeta.

Eduardo Lourenço (1999, p. 10), ao analisar os efeitos da expansão colonial na cultura portuguesa, salienta que, historicamente, parece fazer parte do destino comum do povo português manter-se resguardado em seu próprio imaginário nacionalista. Vivendo, assim, em uma espécie de isolamento sublimado, que ampara e projeta o sonho da nação imperialista, que parte em viagens e conquistas ao redor do mundo ao longo de vários séculos.

Contudo, evitar o destino comum, instalar-se, não se sabe por que aberração ou milagre, às margens do mundo, foi um pouco aquilo que o povo português sempre tem feito. Portugal vivese "por dentro" numa espécie de isolamento sublimado, e "por fora" como o exemplo dos povos de vocação universal, indo a ponto de dispersar o seu corpo e a sua alma pelo mundo inteiro. (LOURENÇO, 1999, p. 10).

Contrariando o sonho expansionista, após abril de 1974 o português se viu presente ou desembarcado em uma nova terra, uma nova realidade, onde as fronteiras são delimitadas e os problemas sociais encontram-se escancarados na sua própria porta, sem a possibilidade de fuga ou regresso ao passado em que dispunha de muitas terras e opções. A geração surgida após a 
Revolução dos Cravos viu-se herdeira de uma pátria pequena e empobrecida frente aos seus vizinhos europeus. A contemplação de um passado gloriosamente imaginado se apresenta como alternativa à melancolia existencial, que acomete o retornado que não encontra uma casa disposta a recebê-lo, e onde ele mesmo não se sente morador e abrigado.

A Lixboa surreal, miserável e destruída torna-se a representação moral da pátria portuguesa após a Revolução e o final do período colonial. Representa o estado deplorável em que o retornado encontra a sua pátria, a sua casa, sempre descrita e imaginada como capital do Império, como grande centro nacional. O Homem de nome Luís, nacionalista ferrenho, ao regressar de Angola para Portugal, depara-se com uma Lixboa transformada em um ambiente de pobreza, e seu imaginário nacionalista não corresponde à realidade dos fatos.

\begin{abstract}
Nunca pensei que Lixboa fosse este dédalo de janelas de sacadas comidas pelos ácidos do Tejo, as vacas sagradas destes rebanhos de eléctricos, estas mercearias de saquinhos de amêndoas e de garrafas de licor, palavra que imaginava obeliscos, padrões, mártires de pedra, largos percorridos pela brisa se destino da aventura, em vez de travessas gotosas, de becos de reformados e de armazéns nauseabundos, palavra que imaginava uma enseada repleta de naus aparelhadas que rescendiam a noz-moscada e a canela, e afinal encontrei apenas uma noite de prédios esquecidos a treparem para um castelo dos Cárpatos pendurado no topo, uma ruína com ameias em cuja hera dormiam gritos estagnados de pavões. (ANTUNES, 2011, p. 122).
\end{abstract}

O romance de António Lobo Antunes faz com que o português, ao final do Colonialismo, se depare com a imagem de si próprio, que rompe com as produções culturais que sempre povoaram o imaginário nacional de Portugal e colaboraram para embasar o nacionalismo presente na identidade nacional.

As naus (2011) visa representar o presente português após o final da ditadura salazarista e do colonialismo africano. Utiliza, também, o passado e o imaginário nacional, mas sem glorificá-lo ou manter uma postura contemplativa e saudosa. O romance concede-para o povo voz e espaço, que durante muitos séculos foram ocultados e abafados em nome de uma visão heroica e epopeica da história nacional.

Os grandes nomes responsáveis pelos descobrimentos portugueses, enaltecidos e marcados pela história nacional, na ficção de António Lobo Antunes são transformados em pessoas comuns, repletas de vícios e problemas e, na maioria das vezes, dotados de um caráter extremamente contraditório aos grandes feitos pelos quais a História lhes consagrou posição de destaque.

As naus (2011) conduz os portugueses a repensarem a sua identidade nacional e o seu imaginário, fazendo com que o país se confronte com o seu próprio passado, e possa, assim, refletir criticamente sobre a história e sobre os grandes nomes que construíram a nação, 
utilizando-se, para tanto, do Colonialismo, da opressão política e de sonhos oníricos, irrealizáveis.

O conhecimento ao mesmo tempo preciso, cruel e lírico dos lados banais, intoleráveis e reveladores da vida - da escondida vida do nosso império solar e hipócrita como poucos -, a sua visão das relações humanas como inextinguível confronto de seres só metaforicamente humanos, a indiferença ao desagrado dos seus humores, opiniões, buñuelescas ferocidades, fazem do seu mundo uma espécie de antimundo ou contramundo da tão decantada "sensibilidade lusitana". Também se lhe perdoou pouco ou nada - fez-se de conta que o livro não existiu - o seu retrato a vitríolo, entre Bosch e Offenbach, da não menos decantada epopeia imperial. E, todavia, enquanto os portugueses não revisitarem aquelas Naus, nunca acordarão do seu histórico sonambulismo. (LOURENÇO, 2001, p. 98).

Eduardo Lourenço (2001, p. 98) destaca a importância da narrativa de António Lobo Antunes para o processo de desconstrução do imaginário nacional português. Segundo ele, a narrativa revela a vida escondida e hipócrita do Império, aclarando, de forma ao mesmo tempo cruel e lírica, o lado sombrio da colonização e o drama nacional dos retornados após a Revolução dos Cravos, em abril de 1974.

O romance de Lobo Antunes desempenha então o papel de uma contranarrativa da nação portuguesa, que efetua uma desconstrução da visão epopeica da história, acordando, assim, o imaginário nacional português do seu estado de saudade contemplativa do glorioso passado, lhe lançando, a partir de seu sonambulismo imperialista, para dentro de um antimundo, revelador da situação social e cultural de Portugal no final do século XX.

\section{Referências}

ANTUNES, António Lobo. As naus. Rio de Janeiro: Objetiva, 2011.

LOURENÇO, Eduardo. O labirinto da saudade. Lisboa: Gradiva, 2007. . Mitologia da saudade. São Paulo: Companhia das Letras, 1999. . A nau de Ícaro. São Paulo: Companhia das Letras, 2001.

SEIXO, Maria Alzira et al. Dicionário da obra de António Lobo Antunes. Lisboa: Imprensa Nacional Casa da Moeda, 2009, 2 v. 